\title{
FAKTOR YANG MEMPENGARUHI LAMANYA PELAKSANAAN INISIASI MENYUSU DINI (IMD) PADA IBU POST PARTUM DI BPM ISTIQOMAH, $S$. Keb.Bd SURABAYA
}

\author{
UKE MAHARANI DEWI \\ UNIVERSITAS NAHDLATUL ULAMA SURABAYA
}

\begin{abstract}
Various programs to support the delivery of ASI has intensified coverage of ASI but still does not meet the expected target. The purpose of this study was to determine the relationship between the mother's attitude, support health workers and support the implementation of those closest to the length of early initiation of breastfeeding on maternal postpartum in BPM Istiqomah, S. Keb.Bd Surabaya. This study is an analityc observational research. Population in this study were all patients post partum in BPM Istiqomah, S. Keb.Bd as many as 15 respondents. Sampling using total sampling. Data collection is done by direct observation by the researcher. Collected data is then processed and analyzed using a computer. Data analysis include univariate analyzes looking for frequency distribution, bivariate analysis with chi square correlation fisher exact test $(\alpha<0,05)$. The results of the bivariate analysis showed a significant relationship (significant) between the attitude of the mother, the support of health professionals, and the support of those closest to the duration of the early initiation of breastfeeding on post partum mothers with significant value smaller than $5 \%$.
\end{abstract}

Key word: attitude, the support of health professionals, and the support of those closest, the duration of the early initiation of breastfeeding.

ABSTRAK : Berbagai program untuk mendukung pemberian ASI telah digalakkan namun cakupan pemberian ASI masih belum memenuhi target yang diharapkan. Tujuan penelitian ini untuk mengetahui hubungan antara sikap ibu, dukungan tenaga kesehatan dan dukungan orang terdekat dengan lamanya pelaksanaan inisiasi menyusu dini (IMD) pada ibu post partum di BPM Istiqomah, S. Keb.Bd Surabaya. Penelitian ini merupakan jenis penelitian observasional analitik. Populasi dalam penelitian ini adalah seluruh pasien post partum di BPS Istiqomah, S. Keb.Bd Surabaya yakni sebanyak 15 responden. Pengambilan sampel menggunakan teknik total sampling. Pengumpulan data dilakukan dengan observasi langsung oleh peneliti. Data yang telah terkumpul kemudian diolah dan dianalisis dengan menggunakan komputer. Analisis data mencakup analisis univariat dengan mencari distribusi frekuensi, analisis bivariat dengan uji chi square korelasi fisher exact test $(\alpha<0.05)$. Hasil analisis bivariat menunjukkan adanya hubungan yang bermakna (signifikan) antara sikap ibu, dukungan tenaga kesehatan dan dukungan orang terdekat dengan lamanya pelaksanaan IMD pada ibu post partum di BPM Istiqomah, S. Keb.Bd Surabaya dengan nilai signifikansi lebih kecil dari 5\%.

Kata Kunci : Sikap ibu, Dukungan Tenaga Kesehatan, Dukungan Orang Terdekat, Lamanya Pelaksanaan IMD 


\section{PENDAHULUAN}

Survei Demografi dan Kesehatan Indonesia (SDKI) 2012 menunjukkan bahwa hanya sekitar setengah anak berumur di bawah dua bulan menerima ASI eksklusif. Persentase ASI esklusif menurun terus setelah dua bulan pertama. Lebih dari tujuh diantara sepuluh anak umur empat sampai enam bulan menerima makanan tambahan (44\%), air putih (8\%), susu formula atau cairan tambahan lainnya (8\%) sebagai tambahan dari ASI atau sepenuhnya sudah disapih (13\%). Hasil telaah dari 42 negara menunjukkan bahwa ASI ekslusif memiliki dampak terbesar terhadap penurunan angka kematian balita, yaitu 13\% dibanding intervensi kesehatan masyarakat lainnya (Roesli,2011).

Rendahnya cakupan ASI eksklusif otomatis meningkatkan angka kematian bayi. Data SDKI 2012 menunjukkan bahwa kematian anak selama lima tahun sebelum survei (merujuk ke tahun 2008-2012) adalah 32 kematian per 1.000 kelahiran hidup, artinya setiap satu dari 31 anak yang lahir di Indonesia meninggal sebelum mencapai umur satu tahun. Bayi mati terjadi pada umur satu bulan sebanyak $60 \%$, menghasilkan angka kematian neonatum sebesar 19 kematian per 1.000 kelahiran hidup. Anak meninggal terjadi saat berumur satu sampai sebelas bulan sebanyak $80 \%$, yang menghasilkan angka kematiaan post neonatum sebesar 13 kematian per 1.000 kelahiran. Perbandingan angka kematian untuk dua survei terakhir menunjukkan kematian bayi dan anak turun sedikit, kecuali kematian neonatum yang tetap konstan.

$$
\text { Upaya pemerintah untuk }
$$
menurunkan angka kematian bayi adalah dengan cara Program Inisiasi Menyusui Dini (IMD). Program Inisiasi Menyusui Dini adalah suatu program pemberian ASI eksklusif secara langsung kepada bayi setelah lahir. Hal ini sangat dibutuhkan, karena bayi setelah lahir langsung mendapat asupan gizi dari ASI (Roesli, 2008). IMD dan pemberian ASI secara eksklusif dapat terlaksana apabila individu, keluarga, petugas kesehatan serta masyarakat sudah memahami tentang pengertian, manfaat, serta tujuan dari IMD dan pemberian ASI secara eksklusif.

Hasil wawancara yang dilakukan oleh peneliti dengan bidan yang menolong persalinan di BPM Istiqomah, S. Keb.Bd Surabaya, didapatkan informasi bahwa bidan melaksanakan IMD pada setiap persalinan dengan waktu pelaksanaan yang bervariatif karena berbagai alasan. IMD memang sedang di galakkan oleh pemerintah, tapi pada dasarnya IMD tidak bisa terlaksana dengan baik. Hasil penelitian yang dilakukan oleh Fifi Indramukti (2012) di wilayah kerja Puskesmas Blado I, dari hasil penelitiannya menunjukkan bahwa faktor yang berhubungan dengan praktik IMD pada ibu pasca bersalin normal yaitu sikap, peran petugas kesehatan dan dukungan orang terdekat. Sedangkan yang tidak berhubungan adalah tingkat pendidikan dan pengetahuan.

Peneliti tertarik untuk melakukan penelitian tentang analisis faktor yang mempengaruhi lamanya pelaksanaan inisiasi menyusu dini (IMD) pada ibu post partum di BPM Istiqomah, $\mathrm{S}$. Keb.Bd Surabaya.

\section{BAHAN DAN METODE}

Lokasi, populasi dan sampel penelitian

Penelitian ini dilaksankan di BPM Istiqomah, S. Keb.Bd Surabaya dan 
dikerjakan dengan menggunakan observasional analitik. Waktu pelaksanaan penelitian dimulai pada tanggal 1 September s/d 10 Oktober 2014. Populasi dalam penelitian ini adalah seluruh pasien post partum di BPM Istiqomah, S. Keb.Bd Surabaya yakni sebanyak 15 responden. Penentuan jumlah besar sampel dengan menggunakan teknik total sampling dimana keseluruhan obyek yang ingin diteliti untuk menjadi sampel adalah semua pasien post partum di BPM Istiqomah, S. Keb.Bd Surabaya yakni sebanyak 15 responden.

Kriteria Inklusi:

1) dilakukan IMD pada ibu post partum

2) Ibu yang bersedia berpartisipasi dalam penelitian ini.

Kriteria Eksklusi:

1) tidak dilakukan IMD pada ibu post partum

2) Ibu yang tidak bersedia berpartisipasi dalam penelitian ini.

3) Ibu yang mengalami komplikasi yang mengancam jiwa.

4) Bayi lahir dengan APGAR < 7

Pengumpulan data

Data sekunder didapatkan dari rekam medis yang ada di BPM Istiqomah, S. Keb.Bd Surabaya, data primer dari observasi yang dilakukan oleh peneliti. Pengolahan data dilkakukan dengan:

1. Editing, koreksi kelengkapan lembar observasi
2. Coding, mengelompokkan dan memberikan kode pada hasil observasi

3. Tabulating, memasukkan data ke dalam tabel untuk memudahkan penganalisaan data.

Analisis Data

Analisis data dilakukan dengan analisis univariat secara deskriptif dengan menghitung distribusi frekuensi dan proporsi, kemudian dilanjutkan dengan analisis bivariat dengan menggunakan uji chi square (x2) yang tingkat kemaknaannya (signifikansi) sebesar 5\% atau 0.05 dan menggunakan perbandingan $\mathrm{x} 2$ tabel. Penggunaan uji dimaksudkan untuk mengetahui terdapat atau tidak terdapat hubungan antara variabel dependen dan independen. Analisis data dilakukan dengan pengujian hipotesis Nol (Ho) atau hipotesis yang ditolak. Dengan menggunakan uji chi- square. Batas kemaknaan $=0,05$, Ho ditolak jika $p<0,05$ dan Ho diterima jika $p>0,05$. Jika $p<\alpha$ $(0,05)$ maka hipotesis nol ditolak dan hipotesis alternatif diterima yang berarti ada hubungan antara sikap, dukungan tenaga kesehatan, dukungan orang terdekat dengan lamanya pelaksanaan IMD. Sedangkan jika $\mathrm{p}>\alpha(0,05)$ maka hipotesis nol diterima dan hipotesis alternatif ditolak yang berarti tidak ada hubungan antara sikap, dukungan tenaga kesehatan, dukungan orang terdekat dengan lamanya pelaksanaan IMD.

\section{HASIL PENELITIAN}

1. Hasil Analisis Univariat

Tabel 1. Distribusi responden berdasarkan kelompok umur ibu post partum di BPM Istiqomah, S. Keb.Bd Surabaya

\begin{tabular}{ccc}
\hline Kelompok umur & Frekuensi & Prosentase $(\%)$ \\
\hline$<25$ tahun & 0 & 0 \\
\hline
\end{tabular}




\begin{tabular}{ccc}
\hline $26-30$ tahun & 12 & $80 \%$ \\
\hline $31-35$ tahun & 2 & $13,3 \%$ \\
\hline 36 tahun & 1 & $6,6 \%$ \\
\hline Total & 15 & $100 \%$
\end{tabular}

Sumber: Data primer tahun 2014

Pada Tabel 1 diketahui 12 responden (80\%) rentang umur $26-30$ tahun, 2 responden $(13,3 \%)$ yang berada pada rentang umur $31-35$ tahun, 1 responden $(6,6 \%)$ berumur $>35$ tahun dan tidak ada resonden $(0 \%)$ yang berumur $>36$ tahun.

Tabel 2. Distribusi responden berdasarkan sikap ibu post partum terhadap pelaksanaan IMD di BPM Istiqomah, S. Keb.Bd Surabaya

\begin{tabular}{ccc}
\hline Sikap ibu & Frekuensi & Prosentase (\%) \\
\hline Baik & 13 & $86,6 \%$ \\
\hline Tidak baik & 2 & $13,3 \%$ \\
\hline Total & 15 & $100 \%$
\end{tabular}

Sumber: Data sekunder

Pada Tabel 2 diketahui 13 responden $(86,6 \%)$ mempunyai sikap yang baik terhadap pelaksanaan IMD, 1 responden $(6,6 \%)$ mempunyai sikap yang cukup baik terhadap pelaksanaan IMD, 1 responden $(6,6 \%)$ mempunyai sikap yang kurang baik terhadap pelaksanaan IMD.

Tabel 3. Distribusi responden berdasarkan dukungan tenaga kesehatan terhadap pelaksanaan IMD di BPM Istiqomah, S. Keb.Bd Surabaya

\begin{tabular}{|c|c|c|}
\hline Dukungan tenaga kesehatan & Frekuensi & Prosentase (\%) \\
\hline Ada dukungan & 11 & $73,3 \%$ \\
\hline Tidak ada dukungan & 4 & $26,6 \%$ \\
\hline Total & 15 & $100 \%$ \\
\hline
\end{tabular}

Sumber: Data sekunder

Pada Tabel 3 diketahui 11 responden $(73,3 \%)$ mendapat dukungan dari tenaga kesehatan terhadap pelaksanaan
IMD, 4 responden $(26,6 \%)$ tidak mendapat dukungan dari tenaga kesehatan terhadap pelaksanaan IMD.

Tabel 4. Distribusi responden berdasarkan dukungan orang terdekat terhadap pelaksanaan IMD di BPM Istiqomah, S. Keb.Bd Surabaya

\begin{tabular}{|c|c|c|}
\hline Dukungan orang terdekat & Frekuensi & Prosentase (\%) \\
\hline Ada dukungan & 9 & $60 \%$ \\
\hline Tidak ada dukungan & 6 & $40 \%$ \\
\hline Total & 15 & $100 \%$ \\
\hline
\end{tabular}

Sumber: Data sekunder 
Pada Tabel 4 diketahui 9 responden $(60 \%)$ mendapat dukungan dari orang terdekat terhadap pelaksanaan IMD, 6 responden $(40 \%)$ tidak mendapat dukungan dari orang terdekat terhadap pelaksanaan IMD.

Tabel 5. Distribusi responden berdasarkan lamanya pelaksanaan IMD di BPM Istiqomah, S. Keb.Bd Surabaya

\begin{tabular}{|c|c|c|}
\hline Lama pelaksanaan IMD & Frekuensi & Prosentase (\%) \\
\hline$<60$ menit & 5 & $33,3 \%$ \\
\hline$>60$ menit & 10 & $66,6 \%$ \\
\hline Total & 15 & $100 \%$ \\
\hline
\end{tabular}

Sumber: Data sekunder

Pada Tabel 5 diketahui 10 responden $(66,6 \%)$ menerapkan IMD selama $>60$ menit, 5 responden $(33,3 \%)$ menerapkan IMD selama $<60$ menit.

2. Hasil Analisis Bivariat

Analisa bivariat digunakan untuk mendapatkan informasi atau gambaran apakah ada hubungan antara variabel independen dengan variabel dependen.

a. Hubungan sikap responden dengan lamanya pelaksanaan IMD pada ibu post partum di BPM Istiqomah, $\mathrm{S}$. Keb.Bd Surabaya.

Tabel 6. Hubungan sikap responden dengan lamanya pelaksanaan IMD pada ibu post partum di BPM Istiqomah, S. Keb.Bd Surabaya.

\begin{tabular}{|c|c|c|c|c|c|c|}
\hline \multirow{3}{*}{ Sikap ibu } & \multicolumn{4}{|c|}{ Lamanya pelaksanaan IMD } & \multirow{2}{*}{\multicolumn{2}{|c|}{ Total }} \\
\hline & \multicolumn{2}{|c|}{$<60$ menit } & \multicolumn{2}{|c|}{$>60$ menit } & & \\
\hline & $\mathrm{n}$ & $\%$ & $\mathrm{n}$ & $\%$ & $\mathrm{n}$ & $\%$ \\
\hline Baik & 3 & $20 \%$ & 10 & $66,6 \%$ & 13 & $86,6 \%$ \\
\hline Tidak baik & 2 & $13,3 \%$ & 0 & $0 \%$ & 2 & $13,3 \%$ \\
\hline Total & 5 & $33,3 \%$ & 10 & $66,6 \%$ & 15 & $100 \%$ \\
\hline \multicolumn{7}{|c|}{$\mathrm{x} 2$ hitung $=6.000, \quad \mathrm{df}=1, \mathrm{p}=0,041$} \\
\hline
\end{tabular}

Sumber: Data sekunder

Hasil uji statistik memperlihatkan x2 hitung sebesar 6.000, sedangkan $\mathrm{x} 2$ tabel berdasarkan $\mathrm{df}=1$ dengan taraf signifikansi 5\% sebesar 3.841 dan nilai signifikansi chi square korelasi fisher exact test sebesar 0.041 . Oleh karena x2 hitung > x2 tabel (6.000> 3.841) dan nilai signifikansi lebih kecil dari 5\% $(\mathrm{p}=0.041<\alpha=0.05) \quad$ maka Ha diterima dan Ho ditolak, artinya ada hubungan yang bermakna (signifikan) antara sikap ibu dengan lamanya pelaksanaan IMD pada ibu post partum di BPM Istiqomah Surabaya.

b. Hubungan dukungan tenaga kesehatan dengan lamanya pelaksanaan IMD pada ibu post partum di BPM Istiqomah, S. Keb.Bd Surabaya. 
Tabel 7. Hubungan dukungan tenaga kesehatan dengan lamanya pelaksanaan IMD pada ibu post partum di BPM Istiqomah, S. Keb.Bd Surabaya.

\begin{tabular}{|c|c|c|c|c|c|c|}
\hline \multirow{2}{*}{$\begin{array}{c}\text { Dukungan } \\
\text { tenaga } \\
\text { kesehatan }\end{array}$} & \multicolumn{4}{|c|}{ Lamanya pelaksanaan IMD } & \multicolumn{2}{c|}{ Total } \\
\cline { 2 - 7 } & $\mathrm{n}$ & $\%$ & $\mathrm{n}$ & $\%$ & $\mathrm{n}$ & $\%$ \\
\hline $\begin{array}{c}\text { Ada } \\
\text { dukungan }\end{array}$ & 2 & $13,3 \%$ & 9 & $60 \%$ & 11 & $73,3 \%$ \\
\hline $\begin{array}{c}\text { Tidak ada } \\
\text { dukungan }\end{array}$ & 4 & $26,6 \%$ & 0 & $0 \%$ & 4 & $26,6 \%$ \\
\hline Total & 6 & $40 \%$ & 9 & $60 \%$ & 15 & $100 \%$ \\
\hline \multicolumn{6}{|c|}{$\mathrm{x} 2$ hitung=10.208 } & ,df $=1, \quad \mathrm{p}=0,007$ \\
\hline
\end{tabular}

Sumber: Data sekunder

Hasil uji statistik memperlihatkan x2 hitung sebesar 10.208, sedangkan $\mathrm{x} 2$ tabel berdasarkan $\mathrm{df}$ $=1$ dengan taraf signifikansi $5 \%$ sebesar 3.841 dan nilai signifikansi chi square korelasi fisher exact test sebesar 0.007. Oleh karena x2 hitung > x2 tabel (10.208> 3.841) dan nilai signifikansi lebih kecil dari $5 \%(p=0.007<\alpha=0.05)$ maka Ha diterima dan Ho ditolak, artinya ada hubungan yang bermakna (signifikan) antara dukungan tenaga kesehatan dengan lamanya pelaksanaan IMD pada ibu post partum di BPM Istiqomah, S. Keb.Bd Surabaya.

c. Hubungan dukungan orang terdekat dengan lamanya pelaksanaan IMD pada ibu post partum di BPM Istiqomah, S. Keb.Bd Surabaya.

Tabel 8. Hubungan dukungan orang terdekat dengan lamanya pelaksanaan IMD pada ibu post partum di BPM Istiqomah, S. Keb.Bd Surabaya.

\begin{tabular}{|c|c|c|c|c|c|c|}
\hline \multirow{2}{*}{$\begin{array}{c}\text { Dukungan } \\
\text { orang } \\
\text { terdekat }\end{array}$} & \multicolumn{4}{|c|}{ Lamanya pelaksanaan IMD } & \multicolumn{2}{c|}{ Total } \\
\cline { 2 - 7 } & $\mathrm{n}$ & $\%$ & $\mathrm{n}$ & $\%$ & $\mathrm{n}$ & $\%$ \\
\hline $\begin{array}{c}\text { Ada } \\
\text { dukungan }\end{array}$ & 1 & $6,6 \%$ & 8 & $53,3 \%$ & 9 & $73,3 \%$ \\
\hline $\begin{array}{c}\text { Tidak ada } \\
\text { dukungan }\end{array}$ & 2 & $13,3 \%$ & 4 & $26,6 \%$ & 6 & $26,6 \%$ \\
\hline Total & 3 & $20 \%$ & 12 & $80 \%$ & 15 & $100 \%$ \\
\hline \multicolumn{7}{|c|}{$\mathrm{x} 2$ hitung=15.039 } \\
\hline
\end{tabular}

Sumber: Data sekunder

Hasil uji statistik memperlihatkan x2 hitung sebesar 15.039, sedangkan $\mathrm{x} 2$ tabel berdasarkan df
$=1$ dengan taraf signifikansi 5\% sebesar 3.841 dan nilai signifikansi chi square korelasi fisher exact test 
sebesar 0.001. Oleh karena x2 hitung > x2 tabel (15.039> 3.841) dan nilai signifikansi lebih kecil dari 5\% $(p=0.001<\alpha=0.05)$ maka Ha diterima dan Ho ditolak, artinya ada hubungan yang bermakna (signifikan) antara dukungan orang terdekat dengan lamanya pelaksanaan IMD.

\section{PEMBAHASAN}

1. Hubungan sikap ibu dengan lamanya pelaksanaan IMD pada ibu post partum di BPM Istiqomah, S. keb.Bd Surabaya.

Hasil penelitian diketahui 13 responden $(86,6 \%)$ mempunyai sikap yang baik terhadap pelaksanaan IMD, 1 responden $(6,6 \%)$ mempunyai sikap yang cukup baik terhadap pelaksanaan IMD, 1 responden $(6,6 \%)$ mempunyai sikap yang kurang baik terhadap pelaksanaan IMD.

Hasil uji statistik memperlihatkan ada hubungan yang bermakna (signifikan) antara sikap ibu dengan lamanya pelaksanaan IMD pada ibu post partum di BPM Istiqomah Surabaya.

Teori yang mendukung hasil penelitian ini dikemukakan oleh Precede yang terdapat dalam Notoatmodjo (2010). Perilaku seseorang dipengaruhi oleh tiga faktor yaitu, faktor predisposisi (pengetahuan, sikap, karakteristik dan demografi), faktor pendukung (pelatihan, sosialisasi) dan faktor pendukung (dukungan petugas, dan dukungan keluarga). Faktor-faktor ini dapat berupa faktor internal dari ibu sendiri yaitu faktor predisposisi, maupun faktor eksternal yaitu faktor pendukung dan pendorong.

2. Hubungan dukungan tenaga kesehatan dengan lamanya pelaksanaan IMD pada ibu post partum di BPM

Istiqomah, S. keb.Bd Surabaya.

Dari hasil penelitian diperoleh data bahwa terdapat 11 responden $(73,3 \%)$ mendapat dukungan dari tenaga kesehatan terhadap pelaksanaan IMD, 4 responden $(26,6 \%)$ tidak mendapat dukungan dari tenaga kesehatan terhadap pelaksanaan IMD.

Hasil uji statistik memperlihatkan bahwa ada hubungan yang bermakna (signifikan) antara dukungan tenaga kesehatan dengan lamanya pelaksanaan IMD pada ibu post partum di BPM Istiqomah, S. Keb.Bd Surabaya.

Teori yang mendukung hasil penelitan ini dikemukakan oleh Arifin (2004) Berhasil atau tidaknya praktek inisiasi menyusu dini di tergantung pada petugas kesehatan baik perawat, bidan atau dokter karena mereka yang pertama akan membanti ibu bersalin melakukan inisiasi menyusu dini.

Petugas kesehatan atau bidan di kamar bersalin harus memahami tatalaksana inisiasi menyusu dini dan laktasi yang baik dan benar, bidan tersebut diharapkan selalu mempunyai sikap yang positif terhadap inisiasi menyusu dini dan ASI eksklusif. Para bidan diharapkan dapat memahami, menghayati dan mau melaksanakannya. Betapa pun sempitnya waktu yang dipunyai oleh petugas kesehatan tersebut, diharapkan masih dapat meluangkan 
waktu untuk memotivasi dan membantu ibu untuk melaksanakan inisiasi menyusu dini Roesli (2008)

3. Hubungan dukungan orang terdekat dengan lamanya pelaksanaan IMD pada ibu post partum di BPM Istiqomah, $S$. keb.Bd Surabaya.

Dari hasil penelitian diperoleh data bahwa terdapat 9 responden (60\%) mendapat dukungan dari orang terdekat terhadap pelaksanaan IMD, 6 responden (40\%) tidak mendapat dukungan dari orang terdekat terhadap pelaksanaan IMD.

Hasil uji statistik memperlihatkan bahwa ada hubungan yang bermakna (signifikan) antara dukungan orang terdekat dengan lamanya pelaksanaan IMD pada ibu post partum di BPM Istiqomah, $\mathrm{S}$. Keb.Bd Surabaya.

Teori yang mendukung hasil penelitan ini dikemukakan oleh Setiyowati (2006) dukungan psikologi dari keluarga dekat terutama wanita seperti ibu, ibu mertua, kakak wanita dan teman wanita yang telah berpengalaman dan berhasil menyusui serta suami yang mengerti bahwa asi baik bagi bayi merupakan dorongan yang kuat bagi ibu untuk menyusui dengan baik.

\section{KESIMPULAN}

1. Terdapat hubungan yang bermakna (signifikan) antara sikap ibu dengan lamanya pelaksanaan IMD pada ibu post partum di BPM Istiqomah Surabaya.
2. Terdapat hubungan yang bermakna (signifikan) antara dukungan tenaga kesehatan dengan lamanya pelaksanaan IMD pada ibu post partum di BPM Istiqomah Surabaya.

3. Terdapat hubungan yang bermakna (signifikan) antara dukungan orang terdekat dengan lamanya pelaksanaan IMD pada ibu post partum di BPM Istiqomah Surabaya.

\section{SARAN}

Peneliti mengajukan beberapa saran, yaitu :

1. Bagi Masyarakat

Kepada masyarakat terutama suami ataupun keluarga terdekat ibu bersalin hendaknya mendukung dengan cara mendampingi saat persalinan berlangsung sehingga IMD dapat berlangsung dengan baik

2. Bagi Tenaga Kesehatan

Diharapkan selalu memberikan dukungan terhadap pelaksanaan IMD dengan cara memberi motivasi dan edukasi pada ibu hamil sehingga saat bersalin nanti dapat dilaksanakan IMD dengan baik.

3. Bagi Peneliti

Beberapa faktor lain yang belum diteliti oleh peneliti berkaitan dengan lamanya pelaksanaan IMD seperti kondisi bayi perlu diadakan penelitian di tempat yang berbeda dengan sampel yang lebih banyak.

\section{DAFTAR PUSTAKA}

Clemens J., Elyazeed R., Rao M. 1999. Early initiation of breastfeeding and the risk of infant diarrhea in rural Egypt. Pediatrics vol. 104 no. 1

Cunningham F. G., Leveno K. J., Bloom S. L., Hauth J. C., Rouse D. J., Spong C. Y. 2013. Obstetri Williams. EGC: Jakarta 
Paket modul kegiatan inisiasi menyusu dini (IMD) dan asi eksklusif 6 bulan. Departemen Kesehatan Republik Indonesia. Jakarta; 2008

Desmawati, 2013. Penentu Kecepatan Pengeluaran Air Susu Ibu. Jurnal Kesehatan Masyarakat Nasiona: Vol.7,No.8

Fajar I, 2009. Statistika untuk praktisi kesehatan, Graha ilmu: Yogyakarta

Survei demografi dan kesehatan Indonesia. Kementerian kesehatan RI. Jakarta:2012

Khanal V., Scott J., 2015. Factors associated with early initiation of breastfeeding in western Nepal. International Journal of
Environmental Research and Public Health: 1660-4601

Moore E.R., Anderson G.C., Bergman N., 2007. Early skin-to-skin contact for mothers and their healthy newborn infants (Review). Cochrane review: 4

Nakao Y., Moji K., Honda S., 2007. Initiation of breastfeeding within 120 minutes after birth is associated with breastfeeding at four months among Japanese women: a self administered quotionnaire survey. International breastfeeding journal: 3(1)

Novita R., 2011. Efektivitas paket 'bunda ceria' terhadap rasa nyeri dan pembengkakan payudara serta produksi ASI pada ibu post partum jakarta 